\section{Optimization of the Sequence of Washing Reverse Osmosis Membranes Used for Seawater Desalination}

\author{
S. Gutiérrez Ruiz, J. A. López Ramírez, M. Hassani Zerrouk, \\ and J. M. Quiroga Alonso \\ University of Cádiz, Faculty of Environmental and Marine Sciences, \\ Department of Environmental Engineering, CASEM, Polígono Río \\ San Pedro s/n, 11510 Puerto Real, Cádiz, Spain
}

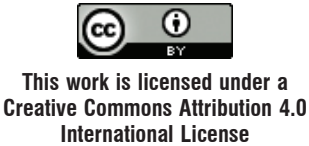

International License

doi: 10.15255/CABEQ.2016.817

Original scientific paper Received: January 23, 2016

Accepted: March 5, 2017

\begin{abstract}
Seawater contains a number of organic and inorganic components that cause fouling of membranes when subjected to a process of reverse osmosis desalination. This fouling is one of the most important problems in the management of desalination plants, as it entails a significant loss in system performance. For membranes to be able to continue operating under appropriate conditions, they must undergo periodic cleaning protocols.

This paper presents the results obtained when, subjecting a previously fouled aromatic polyamide membrane to different washing agents and using different concentrations of the same. Optimal concentrations of cleaning reagents were established.

The results indicate that the performance of cleaning using a mixture of reagents, and alternating alkaline and acidic media, enabled maximum recovery of the membrane permeate flux $(94.2 \%)$ and a significant reduction in the consumption of cleaning reagents.
\end{abstract}

Key words:

reverse osmosis, desalination, fouling, seawater, scaling

\section{Introduction}

Fouling occurs during the operation of seawater desalination plants that employ reverse osmosis membrane technology. ${ }^{1}$ Over time, this fouling results in a gradual decrease in permeate flux and salt rejection, finally causing a significant loss in productivity, which has a negative influence on economics of operating with membranes. ${ }^{2}$ The main causes of fouling include the abundance of colloidal particles, inorganic ions and biological material present in seawater, which are capable of overcoming pre-treatments and subsequently deposited within the elements of the membrane.

Silica colloids and calcium $\left(\mathrm{Ca}^{2+}\right)$, carbonate $\left(\mathrm{CO}_{3}{ }^{2-}\right)$ and sulphate $\left(\mathrm{SO}_{4}{ }^{2-}\right)$ ions play a key role in this process. ${ }^{3-5}$

These ions can be found in seawater at concentrations high enough to reach their solubility limits and thus form precipitates of an inorganic nature on the membranes. ${ }^{6}$ The presence of microalgae in seawater is also a potentially important factor in membrane fouling due to their small size and the possible development of algal bloom episodes at specific times. ${ }^{7}$

Corresponding author, e-mail: santiago.gutierrez@uca.es; Tel.: +34639448240
Removal of these deposits from the surface of the membrane is complex, requiring protocols to carry out periodic cleaning to maintain suitable operating conditions. In general, it is usually considered necessary to clean the system when there is a decrease of 10 to $15 \%$ in permeate flux, a decrease of $10 \%$ in salt rejection or a $15 \%$ increase in differential pressure. ${ }^{8}$

Cleaning occurs as a result of a variety of chemical and physical interactions between the wash solution and the solids present on the surface of the membrane. Multi-step cleaning can represent a useful tool, since the cleaning efficiency can be improved by using different chemicals with complementary cleaning mechanisms. ${ }^{9}$ The key elements of a cleaning strategy are the type and concentration of the cleaning agents, the order and duration of the cleaning stages and the operating parameters of the system during the process. ${ }^{10}$

The overall aim of this study was to optimize the cleaning protocols of membranes that have suffered severe fouling due to the accumulation of salt scale (calcium carbonate and sulphate), silica colloidal particles (Aerosil $\left.{ }^{\circledR} 200\right)$ and microalgae (Nannochloropsis gaditana). To that end, the effectiveness of different sequences of membrane cleaning in a pilot plant was studied, optimizing both the cleaning reagent concentrations and the system operating conditions ( $\mathrm{pH}$ and operation temperature). 


\section{Material and methods}

\section{Methodology applied}

Firstly, the membranes were fouled. A reverse osmosis desalination bench-scale plant (Plant 1) was used for this purpose, passing a feed stream through the membrane consisting of seawater enriched with different chemicals and microbiological agents that commonly cause membrane fouling over a time of around $140 \mathrm{~h} \cdot{ }^{11,12}$ These agents were: inorganic salts (calcium sulphate and calcium carbonate) at an equivalent concentration to their solubility limits (3.16 $\mathrm{g} \mathrm{L}^{-1}$ and $0.03 \mathrm{~g} \mathrm{~L}^{-1}$, respectively), colloidal silica (Aerosil ${ }^{\circledR} 200$ ) at a concentration of 50 $\mathrm{mg} \mathrm{L}^{-1}$ and a culture of the microalga Nannochloropsis gaditana $\left(2 \cdot 10^{6}\right.$ cells $\left.\mathrm{mL}^{-1}\right)$, due to its being a very common alga in the area under study.

Once fouled, the membrane was subjected to a cleaning process in a flow cell plant (Plant 2) using the following physical and chemical agents separately: ethylenediaminetetraacetic acid (EDTA), sodium bisulphite, linear alkylbenzene sulphonate (LAS), citric acid, ammonium hydroxide, temperature and $\mathrm{pH}$. Five solutions of different concentrations of each reagent were tested (Table 1). From the set of trials, the one that achieved the greatest recovery of permeate flux was considered the "limit concentration". The "optimal concentration" was the one that resulted in the greatest recovery of per-

Table 1 - Different concentrations of each reagent used separately in cleaning test

\begin{tabular}{|c|c|c|c|c|c|}
\hline Cleaning reagent & 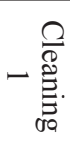 & N & 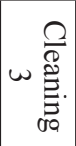 & $+\underset{00}{\stackrel{\rho}{\mathscr{P}}}$ & 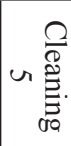 \\
\hline $\operatorname{EDTA}\left(\mathrm{g} \mathrm{m}^{-2}\right)$ & 2.5 & 5 & 10 & 15 & 20 \\
\hline Sodium bisulphite $\left(\mathrm{g} \mathrm{m}^{-2}\right)$ & 2.5 & 5 & 10 & 15 & 20 \\
\hline $\operatorname{LAS}\left(\mathrm{g} \mathrm{m}^{-2}\right)$ & 1 & 2.5 & 5 & 7.5 & 10 \\
\hline Citric acid $\left(\mathrm{g} \mathrm{m}^{-2}\right)$ & 2.5 & 5 & 10 & 15 & 25 \\
\hline Ammonium hydroxide $\left(\mathrm{g} \mathrm{m}^{-2}\right)$ & 2.5 & 5 & 10 & 15 & 20 \\
\hline Temperature $\left({ }^{\circ} \mathrm{C}\right)$ & 19 & 22 & 25 & 32 & 40 \\
\hline $\mathrm{pH}$ & 2 & 4 & 8 & 10 & 12 \\
\hline
\end{tabular}

Table 2 -Combination of cleaning agents at optimal and limit concentrations in sequential cleanings

\begin{tabular}{lcccc}
\hline & Concentration & First & Second \\
\hline Sequential cleaning 1 & Optimal & Basic & Acid \\
Sequential cleaning 2 & Limit & Basic & Acid \\
Sequential cleaning 3 & Optimal & Acid & Basic \\
Sequential cleaning 4 & Limit & Acid & Basic \\
\hline
\end{tabular}

meate flux with respect to the next lowest cleaning trial concentration.

Estimation of optimal and limit concentrations of the cleaning reagents used separately enabled process optimization, choosing those concentrations that combine maximum efficiency with minimum consumption of reagents.

Cleaning trials were subsequently performed using a combination of cleaning agents at optimal and limit concentrations taking into consideration the acid or basic nature of these reagents (Table 2). In summary, the sequential cleaning procedure consisted of applying a double wash, alternating acid or basic mixtures (or vice versa) for a period of 30 minutes each under the different operating conditions shown in Table 2. During the washing process, the $\mathrm{pH}$ of the solution was controlled, thus ensuring its stability around the appropriate value while maintaining the operating temperature constant.

Finally, the washed membrane underwent inspection under a scanning electron microscope in order to compare the development and composition of the depositions cake layers before and after washing.

\section{Description of the desalination plants used}

Two pilot plants were used in the pilot phase. The fouling trials were conducted in a spiral-wound desalination plant (Plant 1, Figure 1) with the aim of causing rapid, severe and homogeneous fouling.

Plant 1 (Figure 1) is an Aqua Frame ${ }^{T M}$ Sea Recovery desalination plant, further equipped with a number of measuring instruments that allow automated monitoring of the main control parameters. It has a stainless steel container for 2421-inch membranes. The pressure system comprises a $0.33 \mathrm{HP}$ output centrifugal pump that provides a feed rate of $570 \mathrm{~L} \mathrm{~h}^{-1}$, followed by a 2 HP CAT piston pump, model 317, stainless made, which raises the feed pressure up to the required 55.16 bars. The buffer tank of the system has a usable capacity of 350 litres and is equipped with a heat exchanger connected to an external cryostat, which enables the feed water temperature to be controlled during the fouling trials. The automated plant control system is equipped with conductivity probes in the feed and permeate streams, electronic turbine flow meters in the permeate and rejection streams and a pressure transducer in the rejection stream. These probes transfer the signal via data loggers to a control computer.

A Hydranautics SWC2-2521 reverse osmosis aromatic polyamide membrane was used. This type of membrane is widely employed in industrial-scale desalination plants and combines high levels of conversion and salt rejection. 


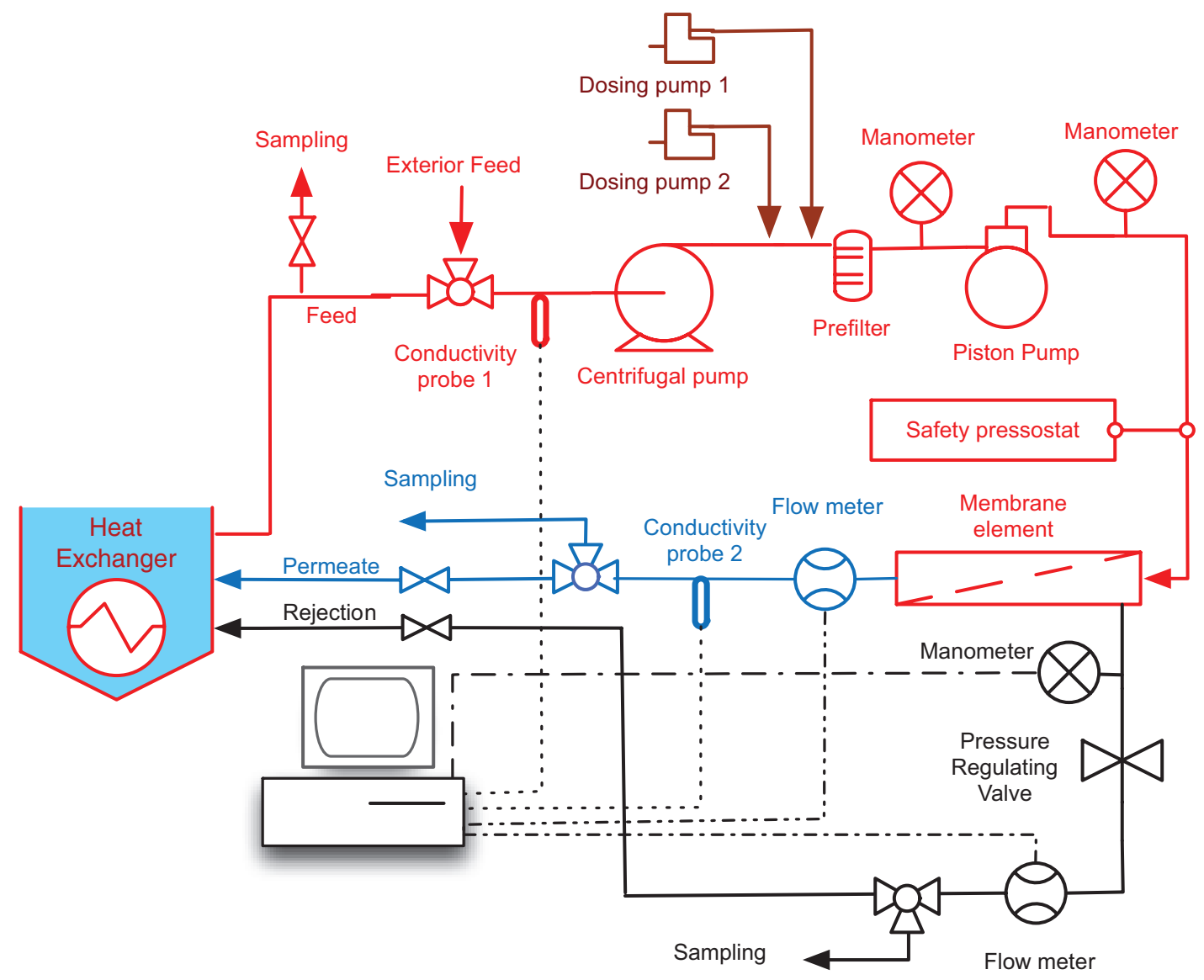

Fig. 1 - Spiral-wound desalination plant

Working conditions were adjusted to the optimum operating conditions established by the membrane manufacturer $\left(55 \mathrm{bar}\right.$ applied pressure, $25^{\circ} \mathrm{C}$ temperature). These parameters were normalized by applying the normalization equations supplied by the membrane manufacturer (Hydranautics).

After fouling, fragments of the fouled membrane were taken $\left(155 \mathrm{~cm}^{2}\right)$ to conduct cleaning trials in a flow cell (Plant 2, Figure 2). This plant is equipped with a $G E$ Osmonics $S e p a^{\circledR} C F$ flow cell and uses a flat-sheet membrane configuration. The facility has a high-pressure CAT piston pump, model 341, controlled by a speed variator that allows the feed flow rate of the system to be controlled. The buffer tank has a volume of 10 litres and is equipped with a heat exchanger connected to an external cryostat to control the feed water temperature.

\section{Reagents used}

The following agents were used in the membrane fouling phase:

- The commercial silica $\left(\right.$ Aerosil ${ }^{\mathbb{}} 200$, Degusta Corp., Akron, $\mathrm{OH}$ ) was used in its powdered form as a colloid model. Use of this colloid is suitable for studying reverse osmosis membrane fouling. ${ }^{13}$
- Precipitated calcium carbonate $\left(\mathrm{CaCO}_{3}\right)$ and calcium sulphate 2-hydrate $\left(\mathrm{CaSO}_{4} \cdot 2 \mathrm{H}_{2} \mathrm{O}\right)$, supplied by Panreac S.A.

- A Nannochloropsis gaditana microalga culture $\left(2 \cdot 10^{6}\right.$ cells $\left.\mathrm{mL}^{-1}\right)$ from the Marine Culture Plant of the Faculty of Marine and Environmental Sciences, University of Cadiz. This is a microalga that is small in size ( 2.5 microns) and has been reported to figure in episodes of bloom. ${ }^{7}$

The following chemical reagents were used in the cleaning phase: Scharlau.

- Hydrochloric acid ( $\mathrm{HCl}): 0.2 \mathrm{M}$, supplied by

- Sodium hydroxide $(\mathrm{NaOH})$ : solid. Minimum purity of $98 \%$. Supplied by Panreac.

- Sodium bisulphite $\left(\mathrm{NaHSO}_{3}\right)$ : Solid. Minimum purity of $98 \%$. Supplied by Panreac.

- Ethylenediaminetetraacetic acid $\left(\mathrm{C}_{10} \mathrm{H}_{14} \mathrm{~N}_{2} \mathrm{Na}_{2} \mathrm{O}_{8} \cdot 2 \mathrm{H}_{2} \mathrm{O}\right)$ : disodium salt dihydrate. Solid. Minimum purity of $99 \%$. Supplied by Panreac.

- Linear alkylbenzene sulphonate (LAS): Sodium salt. Solid with $\approx 80 \%$ mixture of alkylbenzene sulphonates. Supplied by Fluka.

- Anhydrous citric acid $\left(\mathrm{C}_{6} \mathrm{H}_{8} \mathrm{O}_{7}\right)$ : Solid. Minimum purity of $99 \%$. Supplied by Panreac. 


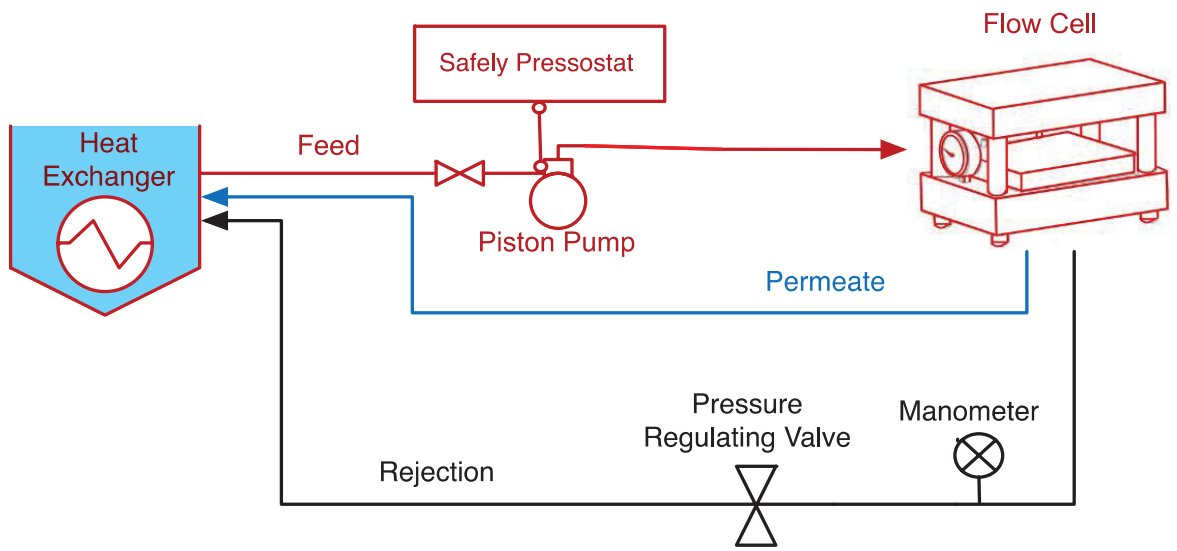

Fig. 2 - Flow cell process scheme

- Ammonium hydroxide $\left(\mathrm{NH}_{4} \mathrm{OH}\right)$ : Liquid (20\%). Supplied by Panreac.

\section{Analytical techniques}

During the fouling process, automated monitoring of the main operating parameters (flow, conductivity and temperature) in the feed, rejection and permeate streams was carried out using the instruments incorporated in the desalination plant for 2521-inch membranes.

In the cleaning trials in the flow cell, the following data were recorded: flow, conductivity, temperature and $\mathrm{pH}$. To do so, a Crison 524 portable conductivity meter microprocessor and a WTW 330-SET 1 high-resolution portable $\mathrm{pH}$-meter were employed.

Metal concentrations in the membrane cake layer were analysed with a Thermo Elemental Iris Intrepid ICP-AES spectrometer Metals analysed were aluminium, boron, barium, calcium, copper, iron, potassium, lithium, magnesium, sodium, silicon and strontium. A Shimadzu TOC-5050A analyzer was used to measure total organic carbon (TOC) and inorganic carbon (IC).

A QUANTA 200 scanning electron microscope equipped with an energy dispersive detector (EDS) for microanalysis of major elements was used to inspect the surface of the fouled and the washed membranes in order to identify the main elements present in the fouling.

\section{Results and discussion}

\section{Membrane fouling}

Figure 3 shows the evolution over time of the flow of both the permeate (expressed as the relative permeate flow rate: $Q / Q_{0}$ ) and the salt rejection for the duration of the fouling trials. During the experiment, different materials (colloids and microalgae) accumulated on the membrane surface, resulting in a $56.7 \%$ reduction in permeate yield. The formation of this fouling layer also caused a slight increase in salt passage through the membrane $(1.63 \%)$, as the salt rejection varied from a baseline of $98.6 \%$ to $96.94 \%$ at the end of the trials.

The chemical composition of the fouling is shown in Table 3. The abundant presence of calcium, potassium, magnesium, sodium and silicon indicates the formation of salt scale and the accumulation of colloidal silica on the membrane. The existence of $10.85 \mathrm{~g}$ TOC per kilogram of fouling indicates the deposition of the microalgae present in the system feed stream.

The SEM micrographs of the fouled membrane (Figure 4a) show a significant layer of fouling deposited on the membrane surface. A basal layer consisting of colloidal silica can be observed that presents a series of cracks caused by material shrinkage during sample drying. A large amount of aggregates and carbonated crystalline growths are deposited on
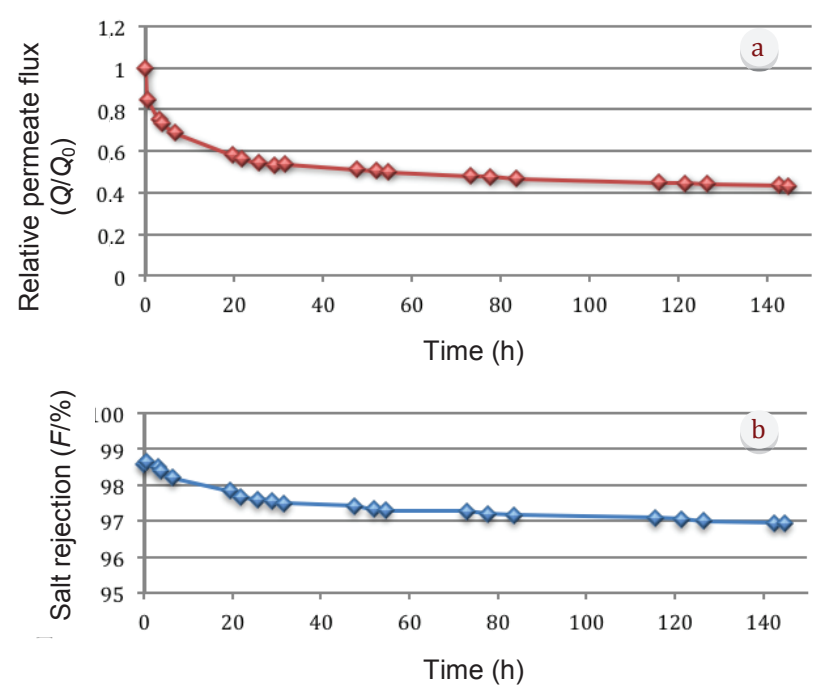

Fig. 3 - Evolution of relative permeate flux $\left(Q / Q_{0}\right)$ and salt rejection $(F / \%)$ in the fouling trials 
Table 3 - Chemical analysis of the fouling

\begin{tabular}{cccccc}
\hline COT & $\mathrm{mg} \mathrm{C} \mathrm{kg}^{-1}$ & 10085.13 & Potassium & $\mathrm{mg} \mathrm{kg}^{-1}$ & 1477.34 \\
Chlorine & $\mathrm{mg} \mathrm{C} \mathrm{kg}^{-1}$ & 3729.13 & Lithium & $\mathrm{mg} \mathrm{kg}^{-1}$ & - \\
Aluminum & $\mathrm{mg} \mathrm{kg}^{-1}$ & 435.94 & Magnesium & $\mathrm{mg} \mathrm{kg}^{-1}$ & 2039.06 \\
Boron & $\mathrm{mg} \mathrm{kg}^{-1}$ & - & Manganese & $\mathrm{mg} \mathrm{kg}^{-1}$ & 3.12 \\
Barium & $\mathrm{mg} \mathrm{kg}^{-1}$ & - & Sodium & $\mathrm{mg} \mathrm{kg}^{-1}$ & 20859.37 \\
Calcium & $\mathrm{mg} \mathrm{kg}^{-1}$ & 14140.62 & Silicon & $\mathrm{mg} \mathrm{kg}^{-1}$ & 1871.09 \\
Copper & $\mathrm{mg} \mathrm{kg}^{-1}$ & 216.4 & Strontium & $\mathrm{mg} \mathrm{kg}^{-1}$ & 210.94 \\
Iron & $\mathrm{mg} \mathrm{kg}^{-1}$ & 34.6 & Dry weight & $\mathrm{g} \mathrm{m}^{-2}$ & 128 \\
\hline
\end{tabular}

this layer, mixed with organic debris. The composition of these layers coincides with the results of EDS microanalysis performed on the sample (Fig-


Fig. 4 - Micrograph (a) and cross-sectional micrograph (b) of the fouled membrane (1000X) ure $8 \mathrm{~b}$ ), showing a major presence of the following elements: carbon, oxygen, silicon, sulphur and calcium. The gold peak is a result of prior metallization of the sample.

A quantitative estimation of the thickness of the fouling layer was made using the cross-sectional micrograph (Figure 4b). This thickness ranged between $15-18$ microns. The thick layer of fouling explains the decrease in permeate production during the fouling trials.

\section{Cleaning trials}

Results of single cleaning reagents

Initially, a series of cleaning trials were carried out using different concentrations of reagents to study their cleaning capacity when acting in isolation (Figure 5). Optimal and limit concentrations of each cleaning reagent were estimated on the basis of these experiments.

For each wash, a solution of $5 \mathrm{~L}$ of cleaning reagent was prepared and stored in the feed tank of the flow cell (Plant 2). After starting up the pump, the system caused the washing solution to pass over the fouled membrane in a closed circuit for $30 \mathrm{~min}-$ utes. At the end of this stage, the remains of the cleaning agent were removed using water. A flow and salt rejection test was then carried out on the washed membrane using the operating parameters set by the membrane manufacturer (feed solution $32 \mathrm{q} \mathrm{L}^{-1} \mathrm{NaCl}$, operating pressure of 55.16 bar and $25{ }^{\circ} \mathrm{C}$ temperature).

Table 4 shows the values chosen as optimal and limit concentrations for each of the physical-chemical agents used. Table 5 presents a comparison of the permeate flux and salt rejection values obtained in the cleaning trials with single cleaning reagents and the values considered as optimal and limit concentrations.

\section{Cleaning with ethylenediaminetetraacetic acid (EDTA)}

Figure 5a shows the permeate flux recorded in the cleaning trials with different concentrations of EDTA. It can be seen that the presence of EDTA in the wash solution causes a significant recovery of permeate flux, even when the cleaning agent con-

Table 4 -Values chosen as optimal and limit concentrations for each of the physical-chemical agents used in sequential cleanings

\begin{tabular}{|c|c|c|c|c|c|c|}
\hline $\begin{array}{l}\text { Concentration } \\
\qquad\left(\mathrm{g} \mathrm{m}^{-2}\right)\end{array}$ & EDTA & Sodium bisulphite & LAS & Citric acid & $\begin{array}{l}\text { Ammonium } \\
\text { hydroxide }\end{array}$ & $\mathrm{pH}$ \\
\hline Acid - Optimal & 5 & 15 & 5 & 5 & - & 4 \\
\hline Acid - Limit & 20 & 20 & 5 & 25 & - & 2 \\
\hline Basic - Optimal & 5 & 15 & 5 & - & 5 & 10 \\
\hline Basic - Limit & 20 & 20 & 5 & - & 20 & 12 \\
\hline
\end{tabular}


Table 5 -Comparison of the permeate flux and salt rejection values obtained in the cleaning trials with single cleaning reagents for the values considered as optimal and limit concentrations

\begin{tabular}{ccc|c|c}
\hline & $\begin{array}{c}\text { Sequential cleaning } \\
\text { concentrations }\end{array}$ & $\begin{array}{c}\text { Permeate flux } \\
\left(\mathrm{L} \mathrm{m}^{-2} \mathrm{~d}^{-1}\right)\end{array}$ & $\begin{array}{c}\text { Permeate flux } \\
\text { decline }(\%)\end{array}$ & Salt rejection $(F / \%)$ \\
\hline Fouled membrane & - & 557.70 & 38.09 & 97.96 \\
\hline \multirow{2}{*}{ EDTA cleaning } & Optimal & 812.04 & 9.86 & 98.81 \\
& Limit & 830.91 & 7.77 & 98.83 \\
\hline \multirow{2}{*}{ Sodium bisulphite cleaning } & Optimal & 732.23 & 18.72 & 98.75 \\
\hline \multirow{2}{*}{ LAS cleaning } & Limit & 752.84 & 16.43 & 98.83 \\
\hline \multirow{2}{*}{ Citric acid cleaning } & Optimal & 837.60 & 7.00 & 98.83 \\
\hline \multirow{2}{*}{ Ammonium hydroxide cleaning } & Limit & 837.88 & 7.03 & 98.73 \\
\hline \multirow{2}{*}{ Temperature cleaning } & Optimal & 744.43 & 17.37 & 98.74 \\
\hline pH cleaning & Limit & 752.07 & 16.52 & 98.65 \\
\hline Clean membrane & Optimal & 661.50 & 26.57 & 98.66 \\
\hline
\end{tabular}

centration is low: for $2.5 \mathrm{~g} \mathrm{~m}^{-2}$ EDTA, the flow loss with respect to the clean membrane was $12.7 \%$. For the trial with $5 \mathrm{~g} \mathrm{~m}^{-2}$, the flow loss was less than $10 \%(9.86 \%)$ (Table 5), which will hence be considered as the optimal washing concentration.

Cleaning with EDTA also resulted in a recovery in salt rejection, obtaining recorded values very close to those of the clean membrane $(98.8 \%)$.

The good performance of EDTA as a cleaning agent can be explained by its chelating effect, being a ligand with a high capacity to sequester $\mathrm{Ca}^{2+}$ and $\mathrm{Mg}^{2+}$ cations, among others, thus reducing the build-up of carbonate and calcium sulphate scale. ${ }^{14}$

\section{Cleaning with sodium bisulphite}

In the case of sodium bisulphite, the improvement in membrane permeability due to the washing effect was lower than that of the other chemical agents used, as can be seen in Figure 5b. When cleaning with concentrations below $15 \mathrm{~g} \mathrm{~m}^{-2}$, only $6.1 \%$ of permeate flux was recovered. Stepping up from 10 to $15 \mathrm{~g} \mathrm{~m}^{-2}$ of reagent led to a significant improvement in washing efficiency, increasing the permeate yield by $13.4 \%$. This was therefore chosen as the optimal concentration of sodium bisulphite. For reagent limit conditions $\left(20 \mathrm{~g} \mathrm{~cm}^{-2}\right)$, recovery of the membrane only increased $2.3 \%$ with respect to the next lowest concentration $\left(15 \mathrm{~g} \mathrm{~m}^{-2}\right)$, which represents a $16.4 \%$ decrease in flow with respect to the clean membrane.
As regards the levels of salt rejection, the membranes washed with sodium bisulphite under optimal and limit reagent conditions showed values ( $98.72 \%$ and $98.75 \%$, respectively) close to those recorded in the clean membrane $(98.9 \%)$.

The cleaning action of sodium bisulphite is closely related to its antioxidant and disinfectant action. Its reducing character allows it to act on the inorganic scale as calcium carbonate and remove metal deposits. Moreover, its biocidal effect may have contributed to reducing the accumulation of microalgae present on the membrane surface.

\section{Cleaning with linear alkylbenzene sulphonate (LAS)}

The presence of this surfactant in the cleaning solutions led to a significant improvement in permeate production (Figure 5c), even at low concentrations, which implies significant recovery of the membrane.

The optimal cleaning conditions may be considered to consist of the use of a cleaning agent concentration of $5 \mathrm{~g} \mathrm{~m}^{-2}$ (Table 5). Under these conditions, a $7.8 \%$ improvement in permeate production was obtained with respect to washing with the next lowest concentration $\left(2.5 \mathrm{~g} \mathrm{~m}^{-2}\right)$. These cleaning results were not improved using higher reagent concentrations. Thus, the optimal and limit concentrations coincide in this case and represent a decrease in flux of only $7 \%$ with respect to the baseline value. 

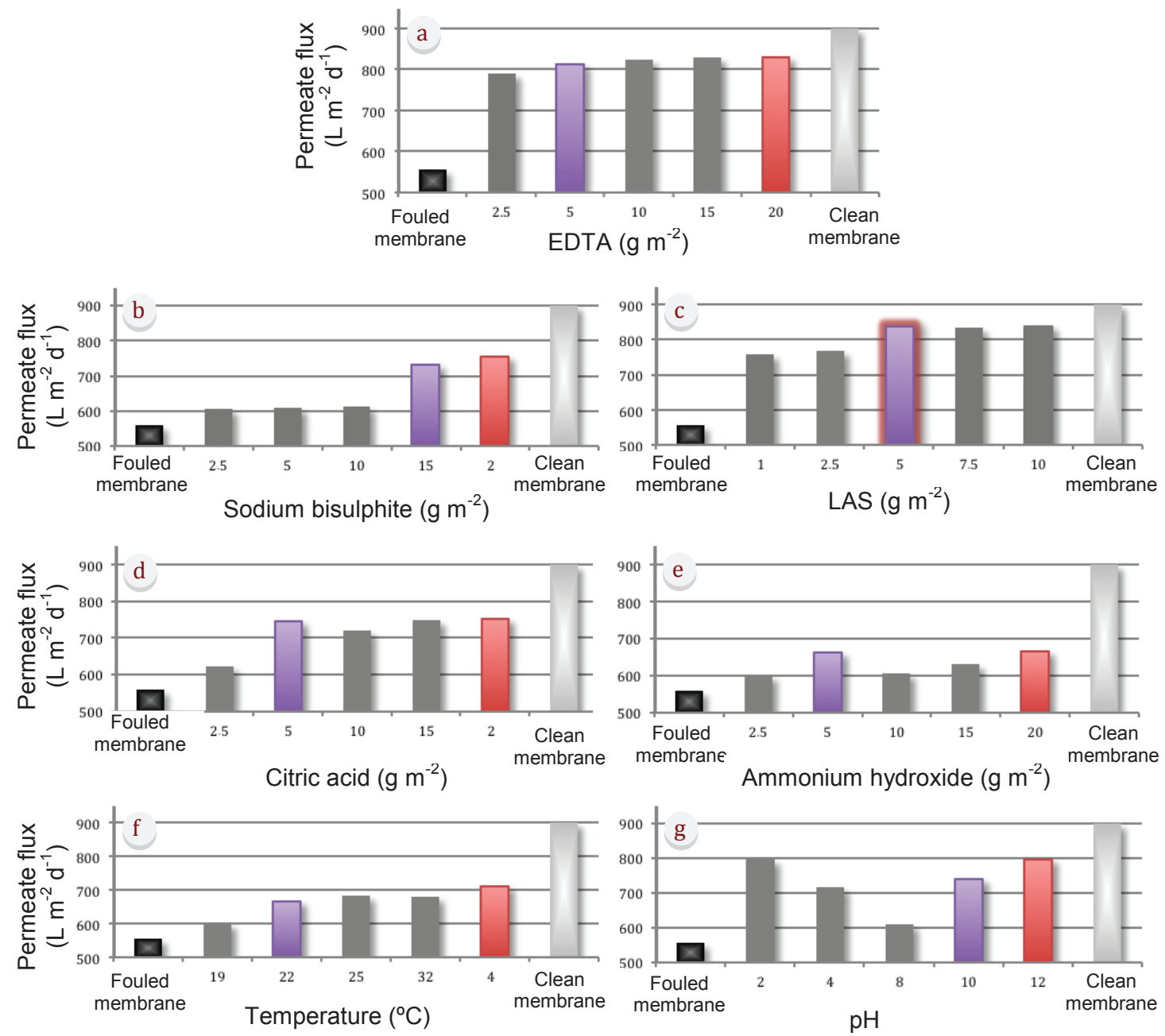

Optimal concentration

Limit concentration

Fig. 5 - Evolution of normalized permeate flux in the cleaning trials with different concentrations of reagents

Levels of salt rejection were almost completely recovered $(98.8 \%)$ for a reagent concentration of 5 $\mathrm{g} \mathrm{m}^{-2}$.

The performance of LAS as a cleaning agent is determined by its action as a surfactant. The micelle formation allow the solubilization of organic fouling.

\section{Cleaning with citric acid}

Figure $5 \mathrm{~d}$ shows the evolution of the permeate flux when washing with citric acid. Cleaning with this agent was moderately effective compared with the other reagents used, showing a decrease in maximum flow of $17.4 \%$ for a concentration of $25 \mathrm{~g} \mathrm{~m}^{-2}$. A concentration of $5 \mathrm{~g} \mathrm{~m}^{-2}$ can be considered optimal, seeing as permeate production improved 13.6 $\%$ under these conditions compared to the trials using a lower concentration.

The rejection levels after washing under optimal conditions were slightly lower $(98.7 \%$ ) than those of the clean membrane (Table 5).
Citric acid constitutes an alternative to commonly used cleaning agents. In aqueous solution, it takes the form of citrate ions, forming salts with a large number of metal ions and promoting the removal of metal oxides and calcium carbonate scale.

\section{Cleaning with ammonium hydroxide}

For this reagent, the recovery levels of permeate flux were the lowest of all the agents used and showed no clear trend (Figure 5e).

The trials using the lowest amount of reagent $\left(2.5 \mathrm{~g} \mathrm{~m}^{-2}\right)$ only achieved an improvement of $4.5 \%$ compared to the fouled membrane. It was necessary to raise the concentration of ammonium hydroxide to $5 \mathrm{~g} \mathrm{~m}^{-2}$ to achieve a significant improvement in production (11.5\%) (optimal concentration). Higher concentrations of the cleaning agent failed to increase the permeate flux, which ranged from $605 \mathrm{~L} \mathrm{~m}^{-2} \mathrm{~d}^{-1}$ of trials using $10 \mathrm{~g} \mathrm{~m}^{-2}$ and $665 \mathrm{~L} \mathrm{~m}^{-2} \mathrm{~d}^{-1}$ of trials using $20 \mathrm{~g} \mathrm{~m}^{-2}$. Permeate production in the trials under limit conditions $\left(20 \mathrm{~g} \mathrm{~m}^{-2}\right)$ was $26.1 \%$ 
lower than that recorded in the clean membrane (Table 5).

Salt rejection reached $99.7 \%$.

The cleaning action of ammonium hydroxide is based on its disinfectant capacity and its behaviour as a weak base. This compound promotes the removal of organic matter and has a significant biocidal action, as well as helps in the removal of calcium sulphate scale. ${ }^{14}$

\section{Effect of temperature}

Figure $5 \mathrm{f}$ shows the permeate fluxes obtained in the trials at different washing temperatures. It can be seen that temperature has a positive effect on the effectiveness of the wash.

At a low temperature $\left(19^{\circ} \mathrm{C}\right)$, the recovery of the membrane is likewise low $(4.8 \%)$. However, raising the wash temperature to $22{ }^{\circ} \mathrm{C}$ produces an improvement in cleaning efficiency, resulting in a $12.0 \%$ recovery in permeate flux compared to the fouled membrane. The optimal temperature was thus $22{ }^{\circ} \mathrm{C}$. Using higher wash temperatures led to a moderate additional increase in production, obtaining the maximum yield in the trial at $40{ }^{\circ} \mathrm{C}$ (limit conditions).

The decrease in flux with respect to the clean membrane varied between 26.1 and $21.1 \%$ in optimal $\left(T=22{ }^{\circ} \mathrm{C}\right)$ and limit $\left(T=40^{\circ} \mathrm{C}\right)$ washes, respectively. In addition, cleaning led to a slight improvement in salt rejection $(98.7 \%$ ).

Increasing the cleaning temperature promotes separation of the layer of organic fouling adhered to the membrane, as well as increases the solubility limits of the salt scale deposited on the membrane, thus favouring dissolution of scaling. However, washing at excessively high temperatures may lead to damage of the membrane structure and so it is essential to follow the manufacturer's recommendations in this respect.

\section{Effect of $\mathrm{pH}$}

To evaluate the influence of $\mathrm{pH}$ on cleaning, the washes were carried out in an acid medium ( $\mathrm{HCl}$ solutions at $\mathrm{pH} 2$ and 4) and in a basic medium $(\mathrm{NaOH}$ solutions at $\mathrm{pH} 8,10$ and 12), as shown in Figure 5g.

It can be seen that the more the $\mathrm{pH}$ values vary from neutral, the greater the effectiveness of the wash. Washing at $\mathrm{pH} 4$ produced an increase in membrane permeability of $17.5 \%$ with respect to cleaning at $\mathrm{pH} 8$; while at $\mathrm{pH} 10$, this increase was $20.4 \%$. On the basis of these data, it can be concluded that washing under optimal conditions was achieved at $\mathrm{pH} 10$.
Trials at $\mathrm{pH} 2$ and $\mathrm{pH} 12$ achieved a slight improvement in the results obtained at $\mathrm{pH} 4$ and $\mathrm{pH} 10$, being slightly more effective than when using a basic $\mathrm{pH}(\mathrm{pH} 12)$. Slightly higher yields were thus obtained under basic conditions than when cleaning in an acid medium.

The salt rejection of the membrane also underwent greater recovery after washing at a $\mathrm{pH}$ far from neutral, regardless of the acid or basic nature of the wash (Table 5).

Depending on the $\mathrm{pH}$ used in the wash, the removal of a particular type of fouling is achieved. While acid cleaning reduces inorganic scale, facilitating the dissolution of carbonates and sulphates, basic cleaning removes organic matter and biological material. Furthermore, basic washing is effective in removing silica, attacking colloidal fouling.

The previously reported considerations, together with the results obtained in the cleaning trials in acid and basic media, lead us to conclude that the application of a sequence of washes alternating acid and basic conditions improves overall cleaning effectiveness, attacking all the forms of fouling present on the membrane.

\section{Sequential cleaning}

Having carried out cleaning trials with different single cleaning reagents, washing experiments were the carried out with mixtures of these cleaning agents at the concentrations considered as optimal and limit values alternating acidic and basic washing sequences. Table 4 shows the sequences employed, while Table 6 presents the results obtained.

It should be noted that, in all cases, the effectiveness of sequential washing improved with respect to that achieved using cleaning reagents. It was found that these sequential cleaning trials provided very positive results in the recovery of the fouled membrane (Figure 6), obtaining a minimum improvement of $31 \%$ in all the washes, while maintaining the permeate flux above $840 \mathrm{~L} \mathrm{~m}^{-2} \mathrm{~d}^{-1}$ (Table 6).

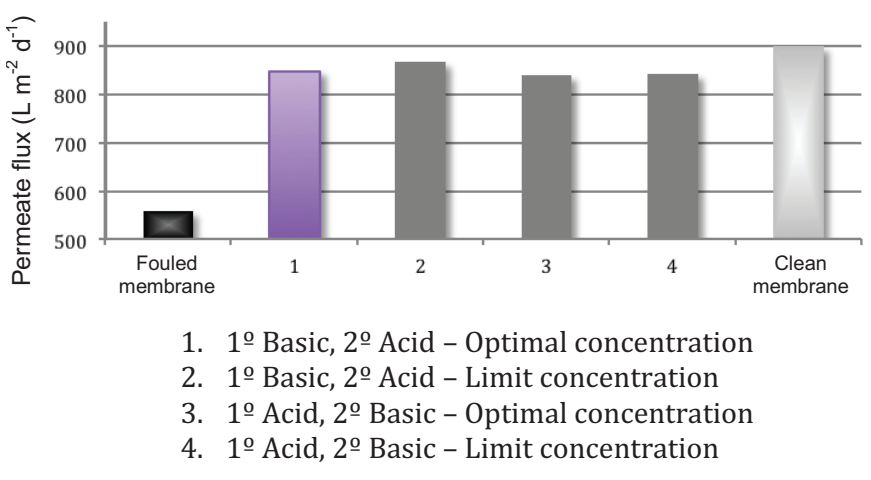

Fig. 6 - Evolution of permeate flux in sequential cleaning 
Table 6 -Comparison of the permeate flux, permeate flux decline and salt rejection values obtained in the sequential cleaning trials

\begin{tabular}{c|c|c|c}
\hline $\begin{array}{c}\text { Sequential } \\
\text { cleaning }\end{array}$ & $\begin{array}{c}\text { Permeate flux } \\
\left(\mathrm{L} \mathrm{m}^{-2} \mathrm{~d}^{-1}\right)\end{array}$ & $\begin{array}{c}\text { Permeate } \\
\text { flux decline } \\
(\%)\end{array}$ & $\begin{array}{c}\text { Salt rejection } \\
(F / \%)\end{array}$ \\
\hline Dirty membrane & 557.70 & 38.09 & 97.96 \\
1 & 848.40 & 5.83 & 98.84 \\
2 & 866.46 & 3.82 & 98.86 \\
3 & 840.46 & 6.71 & 98.83 \\
4 & 842.85 & 6.44 & 98.83 \\
Clean membrane & 900.90 & 0 & 98.90 \\
\hline
\end{tabular}

1. first basic, second acidic - optimal values

2. first basic, second acidic - limit values

3. first acidic, second basic - optimal values

4. first acidic, second basic - limit values

These results prove that the combined use of different cleaning reagents and alternating acid and basic media produce a synergistic effect that enhances the cleaning action.

As to the order of cleaning $\left(1^{\text {st }}\right.$ basic and $2^{\text {nd }}$ acid, or vice versa), the results indicate that both sequences are highly effective, although those washes that began in a basic medium showed a slight advantage (Table 6), which ranged between $0.6-0.9 \%$, depending on whether the washes are analysed under optimal or limit conditions, respectively. This supposes an improvement in permeate flux of between 8.9 and $23.6 \mathrm{~L} \mathrm{~m}^{-2} \mathrm{~d}^{-1}$.

The yield recorded in sequential trials under limit conditions was slightly higher than in the experiments under optimal conditions. This difference ranged from 0.3 to $2 \%$, depending whether washing commenced in a basic or acidic medium, respectively. It is worth noting that Cleaning $1\left(1^{\text {st }}\right.$ basic and $2^{\text {nd }}$ acid, under optimal conditions) yielded a permeate flux of $848 \mathrm{~L} \mathrm{~m}^{-2} \mathrm{~d}^{-1}$, representing a difference of only $5.8 \%$ compared to the results obtained with a clean membrane.

As regards salt rejection, although this parameter did not suffer a major setback during membrane fouling, all the sequential washes practically managed to recover the original levels (Table 6).

In conclusion, it may be stated that the membranes showed good chemical compatibility with the cleaning agents used in the sequential cleaning and under the operating conditions of the system, seeing as degradation or deterioration of the membrane was not detected in terms of its permeate production or salt rejection values.

\section{Microscopic inspection of the washed membrane}

The micrographs of the membrane from Cleaning 1 corroborate a significant reduction in the foul- ing layer (Figure 7a) compared to the fouled membrane (Figure 4) as a result of sequential washing. The presence of aggregates is only observed in specific areas of the washed membrane, in addition to some clusters composed primarily of colloidal silica. Most of the biofouling and salt scale was removed during cleaning.

Figure $7 \mathrm{~b}$ shows a cross-sectional micrograph of the washed membrane, which was used to measure the thickness of the fouling layer that was impervious to washing. As the wash had loosened the fouling layer on a part of the surface, the thickness of the layer could be estimated only in certain areas, not exceeding $2 \mu \mathrm{m}$ in any case. Comparison of this thickness with the values obtained in the fouled membrane (15-18 $\mu \mathrm{m}$, Figure $4 \mathrm{~b})$ confirms that a significant amount of scale was removed during sequential cleaning.

Energy dispersive analysis (EDS) was used to analyse the atomic composition of the surface layer of the membrane, comparing the EDS analyses of the clean (a), fouled (b) and washed (c) membranes (Figure 8). Note should be taken of the absence of

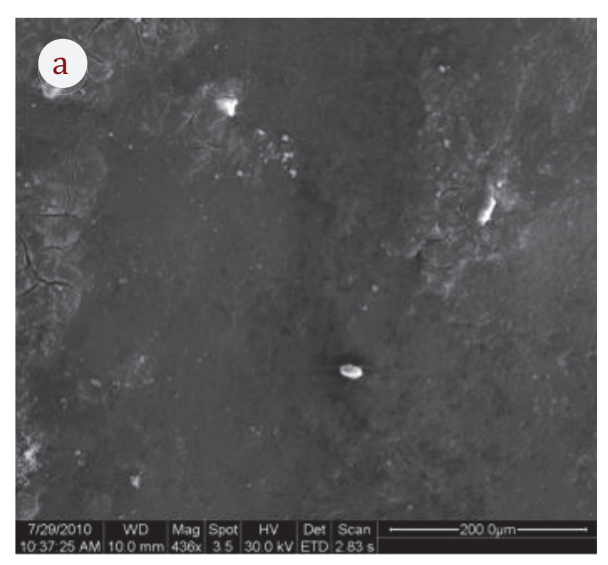

a. Surface micrograph (436x)

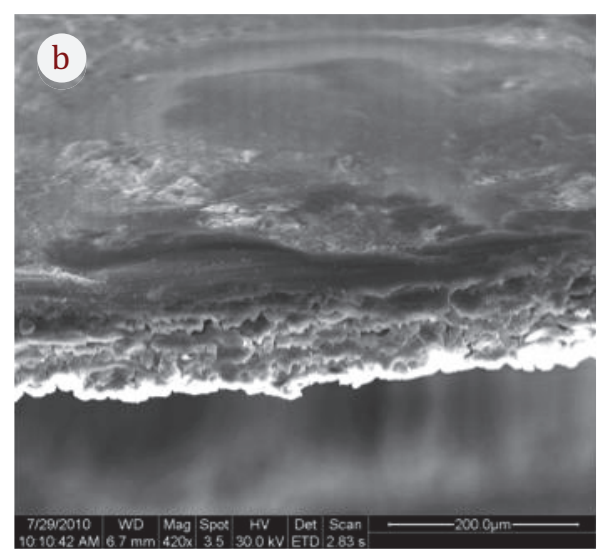

b. Cross-sectorial micrograph $(420 x)$

Fig. 7 -Micrographs of the membrane from cleaning 1 in sequential cleaning 


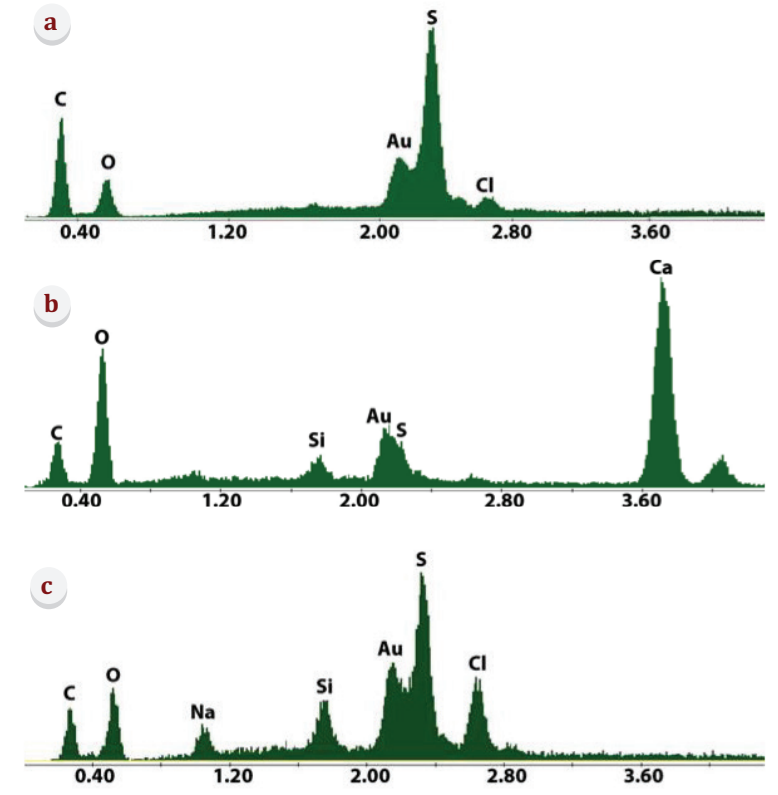

Fig. 8 - Energy Dispersive Analysis (EDS) of the clean (a), fouled (b) and washed (c) membranes

calcium in the washed membrane, confirming a high removal of salts of this element, especially of calcium carbonate and calcium sulphate scale. The structure of the gold and sulphur peaks, which is very similar between the EDS analyses of the clean and washed samples, also confirms the reduction in the fouling layer.

Although sulphur, originating from the structure of the membrane (polysulphone), and gold, which comes from the metallic samples, are clearly identified in the EDS microanalysis of the clean membrane, the accumulation of a thick layer of fouling on the fouled membrane produces shielding of the aforementioned elements due to the relative abundance of other elements characteristic of the deposited fouling such as oxygen, silicon and, above all, calcium.

The silicon detected in the EDS microanalysis of the washed membrane (Figure 8c) indicates the presence of colloidal silica fouling which is impervious to the cleaning process. However, the relative importance of the silica peak is also explained by the scant abundance of other elements due to the reduced fouling of the washed membrane. Therefore, the colloidal silica layer that is impervious to cleaning was probably very small, as confirmed by examination under a scanning electron microscope (Figure 7).

\section{Conclusions}

In view of the results of the present study, the following conclusions may be drawn:
1. The severe fouling caused by the joint action of calcium carbonate and calcium sulphate, colloidal silica and microalgae leads to a drastic drop in permeate flux $(38.1 \%)$ and a slight decrease in salt rejection $(0.9 \%)$ with respect to the results of the clean membrane.

2. Cleaning of the membrane using mixtures of the tested cleaning agents and sequential washing alternating an acid and basic medium (or vice versa) provided an effective method for cleaning reverse osmosis membranes, as it achieved a minimal recovery in permeate flux of $93.4 \%$ under the operating conditions of the system.

3. Sequential cleaning with limit concentrations of reagents achieved an increase of only $0.3-2 \%$ in the permeate flux of the washed membrane with regard to the use of optimal concentrations. Bearing in mind that the latter conditions produced savings in reagents of between $54-57 \%$, it may be stated that the slight superiority of washing under limit conditions would not justify the environmental and economic costs associated with these operating conditions.

4. From the technical, economic, and environmental points or view, the most suitable washing sequence to clean the studied membranes was that using optimal reagent conditions commencing cleaning in a basic medium (Cleaning 1).

\section{References}

1. Song, Y., Gao, X., Gao, C., Evaluation of scaling potential in a pilot-scale NF-SWRO integrated seawater desalination system, Journal of Membrane Science 443 (2013) 201. doi: https://doi.org/10.1016/j.memsci.2013.04.048

2. Sablani, S. S., Goosen, M. F. A., Al-Belushi, R., Wilf, M., Concentration polarization in ultrafiltration and reverse osmosis: A critical review, Desalination 141 (2001) 269. doi: https://doi.org/10.1016/S0011-9164(01)85005-0

3. Park, M., Lee, J., Boo, C., Hong, S., Snyder, S., Kim, J., Modeling of colloidal fouling in forward osmosis membrane: Effects of reverse draw solution permeation, Desalination 314 (2013) 115.

doi: https://doi.org/10.1016/j.desal.2013.01.009

4. Gharfour, E. E. A., Enhancing RO system performance utilizing antiscalants, Desalination 153 (2003) 149. doi: https://doi.org/10.1016/S0011-9164(02)01117-7

5. Taheri, A. H., Sim, L. M., Chong, T. H., Krantz, W. B., Fane, $A$. G., Prediction of reverse osmosis fouling using the feed fouling monitor and salt tracer response technique, Journal of Membrane Science 475 (2015) 433. doi: https://doi.org/10.1016/j.memsci.2014.10.043

6. Hamrouni, B., Dhahbi, M., Thermodynamic description of saline waters - Prediction of scaling limits in desalination processes, Desalination 137 (2001) 275. doi: https://doi.org/10.1016/S0011-9164(01)00229-6

7. Sunda, W. G., Graneli, E., Gobler, C., Positive feedback and the development and persistence of ecosystem disruptive algal blooms, Phycological Society of America 42 (2006) 963. doi: https://doi.org/10.1111/j.1529-8817.2006.00261.x 
8. Fariñas, M., Reverse Osmosis. Fundamentals, technology and applications. Electrotechnologies series, Ed. Mc Graw Hill (1999) 64.

9. Garcia-Fayos, B., Arnal, J. M., Gimenez, A., Alvarez-Blanco, S., Sancho, M., Optimization of chemical cleaning of reverse osmosis membrane from a desalination plant by means of two-step static tests, Desalination and Water Treatment (2014) 1 .

10. D'Souza, N. M., Mawson, A. J., Membrane cleaning in the dairy industry: A Review, Critical reviews in food science and nutrition 45 (2005) 125. doi: https://doi.org/10.1080/10408690490911783

11. Lee, S., Lee, C.-H., Effect of operating conditions on $\mathrm{CaSO}_{4}$ scale formation mechanism in nanofiltration for water softening, Water Research 34 (2000) 3854 doi: https://doi.org/10.1016/S0043-1354(00)00142-1
12. Wang, F., Tarabara, $V$. $V$., Coupled effects of colloidal deposition and salt concentration polarization on reverse osmosis membrane performance, Journal of Membrane Science 293 (2007) 111

doi: https://doi.org/10.1016/j.memsci.2007.02.003

13. Zhu, X., Elimelech, M., Colloidal fouling of reverse osmosis membranes: Measurements and fouling mechanisms, Environmental Engineering Science 31 (1997) 3654. doi: https://doi.org/10.1021/es970400v

14. Siavash Madaeni, S., Mohamamdi, T., Kazemi Moghadam, $M$., Chemical cleaning of reverse osmosis membranes, Desalination 134 (2001) 77.

doi: https://doi.org/10.1016/S0011-9164(01)00117-5 